\title{
Innovation Rhetoric and Reality: An Introduction to the TIM Review's Special Issue on Innovation and Entrepreneurship in Australia
}

\author{
Rowena Barrett
}

\author{
"(nnovation as a term has become meaningless. ") \\ Scott Middleton \\ Chief Executive Officer \\ Terem Technologies (Australia)
}

\begin{abstract}
In this introduction to the Technology Innovation Management Review's special issue on Innovation and Entrepreneurship in Australia, Guest Editor Rowena Barrett reflects on the perceptions of "innovation", both in terms of its evolving concepts and terminology (the rhetoric) and its frontline application (the reality). Prompted by the recent launch and ongoing implementation of Australia Government's National Innovation and Science Agenda's, this special issue focuses on insights into innovation and entrepreneurship from the Australian context.
\end{abstract}

\section{Introduction}

It is rumoured that the word "innovation" was barred from ministerial lexicons during Tony Abbott's terms as Prime Minister of Australia. Now, with Malcolm Turnbull as Australia's Prime Minister, by way of total contrast, it is difficult to find a ministerial utterance that does not connect innovation with jobs and growth. However, as the 2015 Australian Innovation System report makes clear, innovation is a complex phenomenon (Department of Industry, Innovation and Science, 2015).

Innovation exists along a number of axes ranging from radical (or disruptive) to incremental, first-in-organization to first-in-world, product to process, sector to sector, as well as over the lifecycle, and simply a change in focus over time (i.e., design thinking, open innovation). One danger is that innovation is simply reduced to a notion of change. As writers from Marx and Schumpeter to more recently Stan Metcalfe and academics at the Science Policy Research Unit (SPRU; http://www.sussex .ac.uk/spru/) at the University of Sussex have all pointed out, change is endemic to capitalism. Therefore any discussion of innovation must move beyond the obvious threat of tautology.

\section{What Is Innovation - Other than Simply Change?}

Innovation is a poorly defined concept. The meaning of the term varies considerably depending on the context in which it is used, and for what purpose. It is most widely assumed that innovation is about technology and scientific advancements. This view dominates analyses and discussions around policy and regulatory issues, such as intellectual property (IP) protection. This more narrow focus on technological innovation has, unsurprisingly, placed the policy spotlight on the technical skill requirements for innovation, such as skills in STEM (science, technology, engineering, and mathematics). As a result, some governments' policies for promoting growth in STEM skills have called for compulsory science education in schools and at universities, or for students to be introduced to skills such as coding from primary school (Australian Government, 2015; US Government Accountability Office, 2005). These skills are undoubtedly critical to a great deal of new innovation, especially as new technologies disrupt established systems of producing goods and services and challenge traditional business models, but innovation needs to be understood through a lens that is broader than simply technology. 


\section{Introduction to Innovation and Entrepreneurship in Australia}

\section{Rowena Barrett}

The most generally accepted definition of innovation comes from the OECD's Oslo Manual (2005):

"The implementation of a new or significantly improved product (good or service), or process, a new marketing method, or a new organisational method in business practices, workplace organisation or external relation."

This definition captures innovations that are new or significant to the firm, as well as new to the world. It emphasizes innovation as being broader than simply technical breakthroughs and their application in industry. The definition draws attention to implementation of discoveries and highlights the importance of diffusion of innovation.

The definition includes any activity in an innovation process - from the conception of new ideas, inventions, and discoveries; to development and testing; to the production, marketing, and commercialization of those inventions within the ecosystem, not just within particular organizations alone. This also takes us far beyond a simple, technical, and research and development focused view of innovation. These activities in the innovation cycle occur in a dynamic and complex manner, and require the firm to undertake three distinctive sets of activities. Teece (2010) argues these are:

1. Sensing: the identification and assessment of new opportunities for growth and profit

2. Seizing: the mobilization of resources, skills, and capabilities to realize the opportunity and to capture opportunities for creating value

3. Transforming: ongoing efforts to improve and renew the original innovation to sustain the value creating opportunities such innovations present

The Government's Australia Innovation System Report 2015 (Department of Industry, Innovation and Science, 2015) takes a systems approach to innovation, as the report's title suggests. In it, the argument goes that, without understanding how the components of the national innovation ecosystem interact, it is impossible to identify the causes and implications of innovation. The report defines an innovation system as follows:

"an open network of organisations that interact with each other and operate within framework conditions that regulate their activities and interactions. The three components of the innovation system - networks, innovation activities and framework conditions - collectively function to produce and diffuse innovations that have, in aggregate, economic, social and/or environmental value."

Networks includes geographic clusters, business associations, and supply chains. Framework conditions encompass a range of macro-economic, cultural, educational, and policy settings that nurture innovation. Innovation activities can include training, research and development, venture capital investment, and patenting activity.

As Salter and Alexy (2014) have commented, there is a whole industry of consultants and academics putting new words in front of the word innovation (for an extended discussion see Cunningham et al., 2016). Starting with a distinction between incremental and radical innovation (with the recent addition of the concept of disruption), what we have allied to this is the distinction between first-in-organization compared to first-inworld innovation. The concept widened to include service, technological, and organizational innovation. More recently, the concept of open innovation has gained credence with the allied concepts of customer or userlinked innovation. These latter two are also described as hidden innovation. However, this approach is not the only way in which the concept of innovation has expanded.

The above can be contrasted with the Ten Types of Innovation or "the building blocks of breakthroughs", expounded by Keeley and colleagues (2013). The Ten Types are broken down into three categories:

1. Configuration: profit model; network; structure; process

\section{Offering: product performance; product system}

\section{Experience: service; channel; brand; customer engage-} ment

Sophisticated innovation, it is suggested, uses many types of innovation, customized elegantly and orchestrated with care (Keeley et al., 2015). There are similarities and overlaps with the first list but these are not the only choices available. A Google search under "types of innovation", will yield any number of alternative lists and categorizations.

The problem is that the concept of innovation threatens to become, in Andrew Sayer's (1992) terms, a "chaotic concept". This means the concept, while having great 


\section{Introduction to Innovation and Entrepreneurship in Australia}

\section{Rowena Barrett}

political purchase, has little analytical value as it is packed with many differing and sometimes contradictory elements. It lumps together the unrelated and the inessential and divides the indivisible. However, all this notwithstanding, there has never been a more exciting time to launch a national innovation and science agenda.

\section{Australia's National Innovation and Science Agenda}

In December 2015, Australia's National Innovation and Science Agenda was launched with the subheading, "Welcome to the ideas boom" (Australian Government, 2015). A sound bite perhaps, but also a signal to Australians that the resources boom might not be so boomlike anymore! The National Innovation and Science Agenda makes clear that innovation and science are seen to be critical for Australia delivering new sources of growth, maintaining high-wage jobs and seizing the next wave of economic prosperity (Australian Government, 2015). Innovation is viewed as being important to every sector of the economy and is about new and existing businesses creating new products, processes, and business models.

Australia's National Innovation and Science Agenda has four key pillars: i) culture and capital; ii) collaboration; iii) talent and skills; and iv) government as an exemplar. To support the agenda, AUD $\$ 1.1$ billion in funding was allocated to initiatives in these four areas, key aspects of which are outlined below:

1. Culture and capital: this pillar builds on the acknowledgement that Australia has a poor record in converting bright ideas into commercial realities - only 9\% of Australian small and medium-sized enterprises brought a new idea to market in 2012-13 compared to $19 \%$ in the top 5 OECD countries (Australian Government, 2015). Under this pillar, new tax breaks are offered to help overcome what is seen to be a bias against businesses that take risks and innovate. In addition the Commonwealth Scientific and Industrial Research Organisation (CSIRO; csiro.au) and the Biomedical Translation Fund (tinyurl.com/hovnyc7) will coinvest in commercializing promising ideas.

2. Collaboration: this pillar is framed around the understanding that Australia's rate of collaboration between industry and academia is reported to be the lowest across OECD nations (PwC, 2015). The aim here is to encourage researchers and businesses to collaborate. The National Innovation and Science
Agenda promotes partnership-based research for universities and will target investment to what is seen to be critical research infrastructure.

3. Talent and skills: this pillar is almost entirely focused on STEM skills. The first aim of funding initiatives here is to encourage more Australian students to study science, mathematics, and computing in schools. The second aim is to make it easier to attract more entrepreneurial and research talent to come to Australia from overseas.

4. Government as exemplar: under this pillar, the aim is to move government from its position of lagging the private sector in innovation. Funding here is all about helping government to be more innovative in how services are delivered as well as making it easier for startups and innovative small businesses to sell technology services to government.

As part of the National Innovation and Science Agenda's promise, the Government claims that it will make innovation central to all policies. To this end, a new body, Innovation and Science Australia (tinyurl.com/ z6fgxo4) has been established alongside the Digital Transformation Office (dto.gov.au), a Digital Market Place (tinyurl.com/hxqmlja) and a Business Research and Innovation Initiative (tinyurl.com/j7wd822). The Data61 (www.csiro.au/en/Research/D61) data innovation group has been established to help develop new technologybased industries and transform existing ones.

The National Innovation and Science Agenda approach is based on the assumption that problems in innovation can be laid at the door of an unresponsive and over burdensome government/public sector, lack of support for startups, insufficient focus on STEM education (particularly for women), and a lack of encouragement for collaboration, particularly between industry and universities. However, there are indications that the problems might be somewhat more fundamental.

\section{(Mis) management?}

The recently published major study of Australian Leadership at Work (Gahan et al., 2016) suggests there may be more fundamental problems with Australian management. After surveying some 8000 people across 2703 organizations and 2561 workplaces, as well as interviewing people from the top to the bottom of organizations, the conclusion is "Australian leaders, on the whole, have not mastered the fundamentals of management" (Gahan et al., 2016). Gahan and colleagues (2016) 


\section{Introduction to Innovation and Entrepreneurship in Australia}

\section{Rowena Barrett}

identify seven significant gaps and weaknesses, which together are a cause for major concern:

1. Many Australian workplaces are underperforming.

2. Many Australian organizations do not get the basics right.

3. Few Australian organisations report high levels of innovation.

4. Many Australian leaders are not well-trained for the job.

5. Too many Australian organizations under-invest in leadership development, especially at the frontline.

6. Leadership in Australian organizations does not reflect wider social diversity.

7. Many senior leaders do not draw on strategic advice in making decisions about the future.

In many ways, these were the same criticisms of Australian management that were outlined in the 1995 Enterprising Nation report (the Karpin Report). Given the 20-year gap between these studies, the lack of progress is worrying.

Focusing specifically on innovation, and again following the findings of the Karpin Report (1995) as well as Green (2009), the Leadership at Work study suggests that lack of leadership for innovation remains a longstanding challenge. In the report, Gahan and colleagues (2016) conclude:

- Australian organizations struggle to turn knowledge and information inputs into innovation outputs.

- Small organizations struggle most with radical innovation. Public sector organizations score considerably higher on radical innovation.

- Short-term performance is more affected by incremental product and service improvements and is less susceptible to radical innovation

- Highly innovative organizations actively sense, internalize, and act upon new knowledge and changes in their operational environment.

- High-performance work practices relate positively to innovation.
- Employee management based on clear goals produces more innovative outcomes.

In a similar vein, the 2016 American Express CFO Future-Proofing Survey (American Express, 2016) suggests that Australian business may not be on the cusp of an ideas boom, with about $70 \%$ of Australian mid-sized businesses not significantly investing in innovation. This led the Australian Financial Review to speculate as to whether "the Government's ideas boom may be hot air" (Sherbon, 2016) when 40\% of Chief Futures Officers said their organization had failed to bring in any new product or service innovation in the previous three years. Half of all CFOs believed their organizations were not evolving fast enough, and that innovation was an ad hoc rather than strategic activity.

Unsurprisingly, when OECD data was drawn upon, the American Express report concluded that Australia has one of the weakest levels of network and collaborative innovation compared with other OECD countries. This finding helps explain why Australia ranks 21st out of 32 countries for innovation in the OECD ranking (American Express, 2016). This position was acknowledged in the Australian Government's own Australian Innovation System Report. In a world economy increasingly dominated by global value chains, the relative isolation of Australian business from these structures (within which innovation and $R \& D$ are increasingly concentrated) is a matter of concern. This point was stressed in the Australian Innovation System Report (Department of Industry, Innovation and Science, 2014):

"Businesses that participate in global value chains have been argued to be more innovative, more engaged in research and development ( $R \& D)$ and skills development, drive the highest productivity premium, and can support high unit labour costs... Participation in global value chains also drives a step change in business culture by challenging participants to upgrade their management, financing and technology, and encourages greater collaboration... Investing in research and innovation will be the key to maintaining a strong position in a global value chain as a price maker."

However, as a number of commentators point out, Australia is relatively under-integrated into the world economy (see Drake-Brockman, 2014). More particularly, in the 2014 Australian Innovation System Report, it is argued that, according to the OECD's global value chain participation index, Australia's overall participation in global value chains is below the OECD median and well behind global value chain hub countries (Department of Industry, Innovation and Science, 2014). 


\section{Introduction to Innovation and Entrepreneurship in Australia}

\section{Rowena Barrett}

In reviewing the results of the Global Innovation Index (GII), produced jointly by Cornell University, INSEAD, and the World Intellectual Property Organization, Cunningham and colleagues (2016) argue:

"In 2015, Australia ranked 17 overall out of the 141 countries for which a GII score is available, confirming that Australia has established a comparatively healthy environment for enterprise innovation. However, a further breakdown of this index reveals some important points of weakness. Significantly, Australia shows a notable disparity between innovation inputs (ranked 10th) and innovation outputs (ranked 24th), which include technology and knowledge (ranked 39th) and creative outputs (ranked 7th). This implies a lack of 'innovation efficiency'.

While the input measures are generally adequate, Australia performs significantly below its overall ranking on measures capturing the human capital inputs into innovation systems. On the output side, low scores are particularly prevalent in the areas of knowledge impact and knowledge diffusion. Overall, the GII indicates shortcomings in the capacity of Australian enterprise to generate and, more specifically, to bring innovations to application and diffusion. The low scores in business sophistication-especially in innovation linkages (ranked 38th) and knowledge absorption (ranked 63rd)—indicate that rather than lacking skills in general, Australia lacks capacity in using these skills and other inputs for innovation."

Research for the Australian Government suggest that although Australia has a relatively high (but declining) rate of small business formation, only a very small percentage of startups (3.2\%) exhibit serious employment growth and yet this tiny minority accounts for $77 \%$ of total post-entry job creation by micro startups (Hendrickson et al., 2015, 2016).

There appears to be some fundamental issues that go wider and deeper than those identified in the National Innovation and Science Agenda. Since it was announced, there has been an Australian budget handed down, but it was not met with universal approval. Professor Roy Green, Dean of the University of Technology Sydney Business School, suggested "we have to look very hard to find the 'ideas boom' in this budget" (Green et al., 2016), arguing that only AUD $\$ 1$ billion of the AUD $\$ 3$ billion cut in research and innovation expenditure under the previous Abbott government was being restored. Or, as Professor Marek Kowalkiewicz and colleagues from Queensland University of Technology's PwC Chair of Digital Economy team also noted in their assessment of the 2016 Australian budget, it does not address those who face industry and professional disruption due to automation and the changing nature of work (Green et al., 2016).

John Bessant from Essex University has suggested that the Red Queen in Alice in Wonderland is a powerful metaphor for innovation in the modern world (Bessant, 2016). Remember, the Red Queen keeps changing rules, and the game, and this is perfectly normal in Wonderland - and reflects the reality of our own world, it seems. As Bessant argues, "simply recognizing that we need to change what we offer, and how we create and deliver it, isn't going to be enough. We've also got to have the ability to step back and reconfigure our approaches to doing so as the game shifts and the rules change beneath our feet" (Bessant, 2016).

Thankfully, the contributors to this special issue help provide a pathway through this chaos, which reflects both the rhetoric and reality of innovation. Through sharing insights gleaned from the Australian context, we hope the articles in this issue will benefit all players and supporters of the innovation game, with its everchanging rules, wherever in the world it is being played.

\section{About the Author}

Rowena Barrett is Head of the School of Management at Queensland University of Technology (QUT) in Brisbane, Australia. She has played leading roles in organizing, managing, and administering research in universities in Australia and the United Kingdom. Rowena holds a PhD from the University of Melbourne, Australia, on industrial relations in smaller firms, and she has spent many years investigating the ways people in smaller firms are managed and how those firms are organized. She has a sizeable portfolio of research publications including books, book chapters, journal articles, as well practitioner papers and reports. Her research has been funded by university, industry, and government sources in Australia and the United Kingdom. She has extensive experience in teaching in the areas of management, human resource management, and industrial relations, while she has supervised over 10 PhDs to successful completion. She has also held numerous board and council member positions, both within and beyond academia. In 2015, Rowena chaired the ISPIM Innovation Summit "Changing the Innovation Landscape", which took place at QUT in Brisbane, Australia, from 6-9 December. 


\section{Introduction to Innovation and Entrepreneurship in Australia}

\section{Rowena Barrett}

\section{References}

American Express. 2016. Game Plan for Growth: 2016 American Express CFO Future-Proofing Survey. Chief Future Officer; American Express Australia. Accessed April 15, 2016:

http://www.chieffutureofficer.com/

Australian Government. 2015. National Innovation and Science Agenda. Canberra: Commonwealth of Australia, Department of the Prime Minister and Cabinet.

http://www.innovation.gov.au/page/agenda

Bessant, J. 2016. Playing Chess with the Red Queen. The Hype Innovation Blog, June 8, 2016. Accessed June 15, 2016:

http://blog.hypeinnovation.com/playing-chess-with-the-redqueen

Cunningham, S., Theilacker. M., Gahan, P., Callan, V., \& Rainnie, A. Forthcoming in 2016. Skills and Capabilities for Australian Enterprise Innovation. Report for the Australian Council of Learned Academies (ACOLA).

Department of Industry, Science and Innovation. 2014. Australian Innovation System Report 2014. Canberra: Australian Government, Office of the Chief Economist.

http://www.industry.gov.au/innovationreport

Department of Industry, Science and Innovation. 2015. Australian Innovation System Report 2015. Canberra: Australian Government, Office of the Chief Economist.

http://www.industry.gov.au/innovationreport

Drake-Brockman, J. 2014. Advanced Manufacturing Global Value Chains and Policy Implications. In Advanced Manufacturing: Beyond the Production Line: 57-70. Melbourne: Committee for Economic Development of Australia (CEDA).

http://apo.org.au/files/Resource/ceda_advanced_manufacting_201 4_final.pdf

Gahan, P., Adamovic, M., Bevitt, A., Harley, B., Healy, J., Olsen, J. E., \& Theilacker, M. 2016. Leadership at Work: Do Australian Leaders Have What It Takes? Melbourne: Centre for Workplace Leadership, University of Melbourne.

http://sal.workplaceleadership.com.au

Green, R. 2009. Management Matters in Australia: Just How Productive Are We? Findings from the Australian Management Practices and Productivity Global Benchmarking Project. Canberra: Australian Government, Department of Innovation, Industry, Science and Research.

http://www.industry.gov.au/industry/OtherReportsandStudies/Do cuments/ManagementMattersinAustraliaReport.pdf

Green, R., Webster, B., Kowalkiewicz, M., Barrett, R., \& Shahiduzzaman, S. M. 2016. Budget Does Little to Help 'Transition' the Economy. The Conversation, May 3, 2016. Accessed June 15, 2016:

http://theconversation.com/budget-does-little-to-help-transitionthe-economy-57637
Hendrickson, L., Bucifal, S., Balaguer, A., \& Hansell, D. 2015. Employment Dynamics of Australian Entrepreneurship. Research Paper 4/2015. Canberra: Australian Government, Office of the Chief Scientist.

http://www.industry.gov.au/Office-of-the-Chief-

Economist/Research-Papers/Pages/The-employment-dynamicsof-Australian-entrepreneurship.aspx

Hendrickson, L., Bucifal, S., Balaguer, A., \& Hansell, D. 2016. Employment Dynamics of Australian Entrepreneurship: A Management Perspective. Technology Innovation Management Review, 6(6): 33-40.

http://timreview.ca/article/995

Karpin, D. 1995. Enterprising Nation: Renewing Australia's Managers to Meet the Challenge of the Asia-Pacific Century. Canberra: Australian Government.

http://trove.nla.gov.au/version/45053541

Keeley, L., Pikkel, R., Quinn, B., \& Walters, H. 2013. Ten Types of Innovation. New Jersey: John Wiley \& Sons.

OECD. 2005. The Measurement of Scientific and Technological Activities: Proposed Guidelines for Collecting and Interpreting Innovation Data: Oslo Manual. Paris: Organisation for Economic Co-operation and Development (OECD). http://www.oecd.org/sti/inno/oslomanualguidelinesforcollecting andinterpretinginnovationdata3rdedition.htm

PwC. 2015. Innovate and Prosper: Ensuring Australia's Future Competitiveness through University-Industry Collaboration. Sydney: PricewaterhouseCoopers (PwC). http://www.atn.edu.au/siteassets/publications/atninnovateprosp er.pdf

Salter, A., \& Alexy, O. 2014. The Nature of Innovation. In M. Dodgson, D. M. Gann, \& N. Phillips (Eds), The Oxford Handbook of Innovation Management: 26-52. Oxford: Oxford University Press.

Sayer, A. 1992. Method in Social Science. A Realist Approach. Abingdon, England: Routledge.

Sherbon, J. 2016. Government's Ideas Boom May Be More Hot Air than Substance. The Australian Financial Review, May 31, 2016. Accessed June 15, 2016: http://www.afr.com/news/special-reports/culturetech/governments-ideas-boom-may-be-more-hot-air-thansubstance-20160530-gp71rn

Teece, D. J. 2010. Technological Innovation and the Theory of the Firm: The Role of Enterprise-Level Knowledge, Complementarities, and (Dynamic) Capabilities. In B. H. Hall \& N. Rosenberg (Eds.), Handbook of the Economics of Innovation, 1: $679-730$.

http://dx.doi.org/10.1016/S0169-7218(10)01016-6

US Government Accountability Office. 2005. Higher Education: Science, Technology, Engineering, and Mathematics Trends and the Role of Federal Programs. Washington, DC: United States Government Accountability Office. http://www.gao.gov/products/GAO-06-702T 